\title{
Climate Change: Towards Compensating Africa for Economic Growth and Development by Industrialized Countries
}

\author{
Monaheng Mahlatsi \\ National University of Lesotho, Lesotho \\ mahlatsimojo7230@gmail.com
}

\begin{abstract}
On one hand, anthropogenic climate change is real and affecting the world economy in general and Africa in particular. On the other hand, the policy of climate change adaptation as the solution to the problem of climate change is seriously unsuccessful in Africa. Even though climate change is affecting the whole world, Africa is the most vulnerable continent that is economically affected. This is due to a variety of interconnected consequences of climate change such as droughts, floods, desertification, diseases and poor agricultural system including other unknown factors. This article focuses on challenges facing the implementation of climate change adaptation policy in Africa. The implementation of the policy of mitigation of greenhouse gas emissions will not be discussed. The aim of the article is to investigate the underlying implications of climate change adaptation policy that hamper smooth growth and development of the African economy. To achieve this aim, the theoretical research method will be utilized. This article concludes that Africa cannot afford to adapt to climate change because of its extreme poverty and will remain economically poor and suffer the consequences of climate change if industrialized countries are reluctant to compensate it. Therefore, the article argues that industrialized countries have a moral duty to compensate Africa for the harm they have caused through industrialization. The compensation will boost the African economy that is necessary for climate change adaptation.
\end{abstract}

Keywords: Climate change, adaptation, African compensation, African economic growth, industrialized countries.

\section{Introduction}

The anthropogenic (man-made) climate change is real. It is affecting the world in general and Africa in particular. There are observable consequences of climate change such as droughts, floods, desertification, diseases and poor agricultural systems to mention a few. These consequences force the African economy to decline. The declining African economy calls for immediate action to be taken. Failure to take immediate, necessary and accurate measure to address this problem will lead to the destruction of the present and future African well-being. Climate change adaptation policy has been recommended and accepted by most rich countries as a solution to the problem of climate change. However, the implementation of the policy requires strong financial power and this implies that Africa cannot afford but only rich countries can. Now, the salient question is; if Africa was a participant in finding the solution to the problem of climate change, would it prefer adaptation to climate change as the best solution yet it is economically weak? The inability of Africa to implement the policy may give room to the feeling that the policy was imposed and it was foreseen that Africa will not afford to implement the change hence it will be forced to continue to economically depend on rich countries. In the light of the foregoing, the policy of climate change adaptation is seriously unsuccessful in Africa. Climate change continues to negatively affect the African economy. In the same manner, the African economy continues to deteriorate to the level of extreme poverty.

Understanding Global Warming and Climate Change: An assessment report of the Intergovernmental Panel on Climate Change (IPCC) 2007 provides observed changes in climate system together with effects of those changes. According to the report, there is scientific evidence about increases in global average air and ocean temperatures, rising global average sea level and global melting of snow. This scientific evidence is proof that climate change is globally happening with devastating effects. The report further concludes that the cause of climate change is the continuous global emissions of Greenhouse Gases (GHGs) such as Carbon dioxide $\left(\mathrm{CO}_{2}\right)$, Methane $\left(\mathrm{CH}_{4}\right)$ and Nitrous Oxide $\left(\mathrm{N}_{2} \mathrm{O}\right)$ into the atmosphere. As compared to other Greenhouse gas emissions, Carbon dioxide emission is the top on the list since it increased by $80 \%$ between 1970 and 2004 due to human activity. Anthropogenic climate change in this context refers to the long-term variation of the climate system that is significantly influenced by human activity through Greenhouse gas emissions (Pojman, 2008: 572-573, Van De Veer et al., 2003: 620-621). A distinction between concepts of 
global warming and climate change should be made since both concepts are sometimes used interchangeably yet they are two different phenomena. Thus, global warming refers to the increasing global average surface temperature while climate change is variations in global climate which is caused by increasing global average surface temperature (Pojman, 2008: 576). This implies the cause-effect relationship between global warming and climate change. In other words, global warming is the cause of climate change hence global warming and climate change are interrelated and interconnected. Therefore, it is due to their relationship that they are confused and used interchangeably. Having made the distinction between global warming and climate change, the discussion will extend to consequences and implications of climate change for Africa.

\section{Consequences and implications of climate change for Africa}

Africa will suffer the consequences of climate change even though it is not the main contributor to global warming (Brunner et al., 2005: 173). It is certain that Africa is more vulnerable to impacts of climate change than other regions globally. Amazingly, climate change has a threatening potential of destroying the future wellbeing of Africans, ecosystems as well as the socio-economic development of the entire continent (Van Wyk, 2010: 3). There are important projections concerning climate change in Africa and they should not be ignored by the international community and industrialized societies. It is projected that, areas over the Sahara region and semi-arid areas of Southern Africa will experience a temperature increase of $1.6^{\circ} \mathrm{C}$ by 2050s while equatorial areas will be $1.4^{\circ} \mathrm{C}$ (Hulme et al., 2009: 33). Moreover, it is also projected that the sealevel rise at the African coastline will be about $25 \mathrm{~cm}$ by 2050 (ibid). At this juncture it must be emphasized that Africa, more especially the Sub-Saharan, has no power to prevent climate change hence it is only left with responding to it (Brunner et al, 2005: 176). This implies climate change adaptation. It does not imply mitigation because Africa is not one of the industrialized continents hence it has nothing to mitigate as far as mitigation of carbon dioxide emissions is concerned.

Countries in this region are not even ready to prevent climate change because they are busy struggling with consequences not causes of climate change, which they are unable to address. Therefore, this leaves them in more jeopardy and extreme poverty (ibid). The driving force behind more vulnerability to climate change in Africa is extreme poverty. For example, livelihoods in Africa depend hugely on natural resources, more especially in rural areas since they rely on agriculture, forestry and fisheries. Furthermore, climate change brings about extreme weather conditions that are difficult for African governments to predict while weather is very significant in agriculture (Smith, 2006: 8). Again, most people in Africa live in areas that are exposed to droughts and desertification (Brunner et al., 2005: 176). What makes matters even worse is that, the average per capita income in Africa appears to be the lowest as compared to other countries of the world. Therefore, this limits Africa to rebuild livelihoods after the hazardous impacts because of poor financial resources and this is exactly what makes poverty reduction and Millennium Development Goals futile in Africa (Smith, 2006: 9). Major lethal climate change consequences that face Africa are as follows: droughts, floods desertification health agriculture and food insecurity.

Droughts: High-temperature increase results in increased evaporation hence the likelihood of drought. (Smith, 2006: 21). Clearly, the increase in evaporation coupled with temperature increase affects water availability. For this reason, climate change has a strong influence on the flow of water in rivers, water availability and the quality of water. Therefore, most regions in Africa that have low rainfall suffer water stress hence drought. According to the IPCC Synthesis report, (2007) it is estimated that, between 75 and 250 millions of people in Africa will be exposed to severe water stress by 2020 due to the influence of climate change. To be more specific, it is projected that, due to lower precipitation in Lesotho where water is a crucial and most abundant resource, there is a likelihood of reduced availability of fresh water due to climate change (Mwangi in Van Wyk, 2010: 45). It is without a doubt that, water stress will affect access to fresh drinking water, agriculture and sanitation in Africa. These will directly affect food production and human health that will result in hunger, diseases and ultimately deaths.

Floods: Armah (2005: 204-205) argues that coastal areas in Africa are vulnerable to floods due to sea-level rise and it is projected that, these areas will be severely flooded as the sea level rises up to a meter in the next decades. Areas that are likely to be affected most by floods in Africa are mainly coastal areas of West Africa and physical changes that would threaten coastal habitats and ecosystems are expected. Changes include 
coastal erosion, damage of infrastructure, and sea water intrusion into the fresh water system, sewage system breakdown and loss of ecosystems.

Desertification: Climate change has affected and will continue to affect Africa with desertification and its implications. Scientific research on the issue of desertification and its implications in Africa has been done and it has been found that desertification is real and continuing. The general observation is that, Sub-Saharan desertification, as it continues, leads to moisture and rainfall reduction in the northern Sahel while it increases moisture and precipitation in the southern part of it (Balling Jr, 2005: 43). Moreover, research has also revealed that, the increase in temperature in most African regions causes the increase in evaporation hence reduction in the levels of soil moisture. In this regard, it is projected that the soil moisture level in most sub-Saharan regions will decrease by less than $1 \mathrm{~cm}$ while the northern Sahel will experience a reduction of up to $3 \mathrm{~cm}$. Again, a bigger portion of the Western half of Southern Africa soil moisture will decline up to 1 to $2 \mathrm{~cm}$. Eastern Southern Africa will see few centimeters increase in soil moisture (ibid, 47). It is clear that, regions that will experience increased soil moisture and precipitation will experience floods while those with reduced soil moisture and precipitation will see droughts and desertification that will negatively affect access to clean fresh drinking water, agriculture, sanitation and human health in Africa.

Health: Climate change has a direct impact on human health imposed by rising temperature and shortage or too much water. The consequences of climate change for Africa in particular are very serious and threatening. For example, it is expected that, with changing rainfall patterns, a population of disease-carrying mosquitoes will multiply and result in increased malaria. This will be accompanied by the increase of water, food and vector-borne diseases such as cholera due to water contamination caused by increased floods and unhygienic practices when there is no water. Changing precipitation patterns will also reduce agricultural production and food distribution throughout the continent. It is projected that between 75 and 250 million people on the continent will be exposed to water stress by 2020. Consequently, malnutrition and hunger will increase due to reduced food production and distribution. This will negatively affect both physical and intellectual progress in children, adult productivity, increased diseases hence deaths. (Smith, 2006: 24)

Agriculture and food insecurity: A large number of the population of Africa relies on rain-fed agriculture and it is clear that any change of precipitation pattern will affect agriculture. For example, about 70 percent of the African population relies on agriculture and 40 percent of agricultural production is exported. Climate change will affect food supply by changing precipitation patterns and such changes will result in devastating consequences such as increased floods and droughts. It is projected that in some countries where yield depends on rainfall, agricultural production and access to food will be reduced by up to $50 \%$ by 2020 . Climate change will also affect food supply through farming systems. It will affect farming systems by altering planting dates, methods, crop suitability shift and increased temperature may result in livestock deaths (Smith, 2006: 22). This will also reduce agricultural production and lead to the food shortage in Africa. Another major threat coupled with food shortage will be the rising of food prices. Thus, "...food prices would rise globally with increases of global average temperature of a few degrees or more because of a slowing in the expansion of global food supply relative to population growth" (ibid). While climate change is affecting the African economy and wellbeing through droughts, floods, desertification, health, agriculture and food insecurity, an amicable solution is not yet made to address the problem of climate change in Africa. Instead, the problem of climate change is overwhelmed by unending debate. Now, the discussion will move to the climate science debate.

Climate science debate: Climate science debate emerged in 2007 when the IPCC released its Fourth Assessment Report indicating that climate change is real as a result of the observed rising global average temperatures starting from the mid- $20^{\text {th }}$ century. It further states that the observed increase in global average temperatures is without doubt due to the anthropogenic Greenhouse gas emissions as agreed by scientists. Consequently, the IPCC and Al Gore were awarded a Noble Peace Prize for their scientific work on climate science in October 2007. Al Gore had released a documentary in 2006 titled: "An Inconvenient Truth" which argued that the anthropogenic climate change is real and if immediate steps are not taken for reducing Greenhouse gas emissions, devastating climate changes would cause havoc in human societies hence the fall in industrial development. In response to the findings of Al Gore and the IPCC, a number of scientists grouped together and established a group known as Nongovernmental International Panel on Climate Change (NIPCC) 
in order to make a report that would challenge the scientific findings behind the anthropogenic climate change. Floods will not only affect the coastal habitats and their species, but will also damage livelihoods that depend on them (Smith, 2006: 23).

For example, livelihoods of people in the coastal area of Ghana depend on coastal habitats and their species such as the production of certain fish (Armah, 2005: 204). Clearly, floods will result in hunger, diseases, extreme poverty and deaths in flooded areas in Africa. Their report titled: "Nature, Not Human Activity, Rules the Climate" was published on the $2^{\text {nd }}$ March 2008 by Heartland Institute (HI). Eventually, both sides of the climate science debate agree that Greenhouse gases such as Carbon dioxide $\left(\mathrm{CO}_{2}\right)$ and Methane $\left(\mathrm{CH}_{4}\right)$ as well as global average temperatures have notably increased as from early $20^{\text {th }}$ century. Despite their agreement, the prevailing climate science debate is based on the question of whether climate change is a natural or manmade phenomenon. Even though the IPCC claim that there is a "scientific consensus" over the reality of Anthropogenic Climate Change (ACC), this is disputed by climate change denialists. Climate change denialists argue that climate change has happened is happening and it will continue to happen even in the future. For example, they emphatically argue that human emissions of Carbon dioxide and warming trends occurred a long time ago even before industrialization. Moran, (2010: 24) argues that temperatures in the Roman warming about $250 \mathrm{BC}$ were $2^{\circ} \mathrm{C}$ to $6^{\circ} \mathrm{C}$ warmer than today and there is scientific proof that cooling had happened in the past five years which proofs the future inevitable cooling.

In the same manner Ball (2014) argues that the deception that human activity causes global warming or climate change was deliberately designed to be global through United Nations agencies such as the IPCC. According to Moran, (2010: 30) the purpose of deception is to make people in the whole world think that the world is approaching a devastating stage of warming which humans can actually stop yet there is no convincing evidence. Moreover, he argues that the sole purpose for using climate change science and IPCC as political instruments is simply that the West wants to continue to have full control over Africa. To achieve their objective, they have hijacked climate science and established a new shift to environmentalism. Surprisingly, climate science scientists have even made a "consensus" that climate change is man-made. This behavior is highly questionable since science is always hypothetical but their science has found the so-called "truth" that climate change is anthropogenic. In the light of the above, climate science debate has implications for Africa that need to be taken seriously. The discussion will now extend to implications of climate change debate for Africa.

\section{Implications of the climate science debate for Africa}

The current dominance of the Western epistemological model for understanding global warming and climate change is imposed upon Africa without giving its leaders a chance to share their worldview with Western leaders. Climate change consensus which has been influenced by the Western worldview may be considered as a form of Neo-colonial thinking and manifestation of philosophical racism that undermines African sovereignty. In the African context, African sovereignty is understood as a right and power of Africa to govern itself without interference by other external powers while Neo-colonialism refers to "the de facto renegotiation of the colonial status" (Eze, 1998: 248). In Other words, Neo-colonialism represents Colonialism in the contemporary world whereby, a State which used to be a colonial territory is independent in theory alone. That is to say, its socio-economic policies and systems are still controlled by the external colonial power and this control is irreversible. Philosophical racism refers to the characterization of Africans as sub-humans due to complete lack of reason since according to the Western worldview; to be human is to possess reason (Ramose, 1999: 12). Combined together, Neo-colonial thinking and philosophical racism affect African sovereignty and well-being.

This is done through the deprivation of African political and economic development hence a direct violation of a right to life. Therefore, the imposed man-made climate change thesis is just an excuse on the part of the Western industrialized world to stop Africa from industrializing or developing and by implication, preventing Africa from effectively overcoming the problem of poverty. Climate science debate has political and economic implications that are interconnected for the African continent. The political implication is that, if Africans through the influence of their political leaders and media accept the argument that climate change is a natural phenomenon, they reject Neo-colonialism and its effects. On the contrary, if they accept the argument that 
climate change is man-made, the implication is that they accept and give room to Neo-colonialism that is characterized by evils such as; dictatorship by the West, dependency on the West, internal and external conflicts, corruption, poverty and poverty-related diseases as well as starvation that will lead to gradual disappearance of the African States.

Furthermore, the economic implication of the conception that climate change is man-made is that there should be absolute cuts of Carbon dioxide emissions. The aim of this idea is simply that climate change extremists should acquire an absolute reform of world economies in the name of environmentalism. This implies the collapse of industrialization in the non-Western world and this is a good tool of keeping the nonWestern world underdeveloped yet there is a demanding responsibility for intelligent political leaders to develop their world. The initiative for the regulation and legislation of Carbon dioxide will have a negative economic impact on Africa. Once this idea is implemented, food prices and other commodities will increase and the non-Western world will not afford expensive necessities such as food, clean water, and electricity as well as good health services. Therefore, the regulation and legislation of Carbon dioxide emissions will result in an unnecessary disruption of economies and wellbeing of people in the non-Western world. Now, climate science debate raises three basic doubts. The first is that science is normally based on hypothetical facts not consensus, but seemingly, climate change science is based on consensus. This science is highly questionable since it has found the so-called "truth" that climate change is anthropogenic. Now, questions arise: why did the findings become a consensus? Was it not for the purpose of silencing the critics in order to have the position of climate science prevailing as the "only truth?" How credible are the findings since science is always hypothetical in seeking the truth?

If climate science has uncovered the "truth", how did it arrive at that truth? Above all, why that finding is universalized and imposed? What are climate scientists hiding? Is it not for the reason of ruling out the possibility of inter-cultural dialogue about the problem of climate change? Secondly, why does climate science focus only on anthropogenic global warming not natural causes or both? Thirdly, climate change has happened, is happening and it will continue to happen even in the future. Thus, warming trends occurred even before industrialization as well as human emissions of Carbon dioxide and there is scientific proof that cooling had happened in the past few years which proofs the future inevitable cooling. Now, the question is: if warming trends occurred even before industrialization, how true is the so-called "scientific consensus"? In the light of the above doubts one may argue that climate change consensus has a hidden agenda behind climate science and environmentalism against developing nations. These doubts do not only uncover the hidden agenda about climate change consensus but also reveal serious political implications that are not for the benefit of the African continent. For example, climate change consensus urges Africans to resist industrialization because of a threat that human activity through industrialization cause climate change. Now, it logically follows that if African leaders accept this argument, they will be choosing poverty on the part of Africa - a choice which is indirectly imposed by devising a threat. Consequently, this choice will force African leaders to always seek economic aid from the West thereby prolonging African dependency in the form of Neo-colonialism which will continue to undermine the African sovereignty. At this juncture, the discussion will move to the issue of compensating Africa for economic growth and development.

Towards Compensating Africa for Economic Growth and Development: There is a huge amount of Greenhouse gases emitted by industrialized societies. The issue of stabilizing the amount of greenhouse gases in the atmosphere has become a global political concern. As a result, industrialized societies have a moral obligation to lead the initiative of reducing carbon dioxide emissions since they are the ones responsible. A significant initiative in an attempt to address the problem of climate change was realized by the establishment of the IPCC in 1988. One of its objectives was to assess and formulate possible and necessary responses as well as strategies that can be utilized to stop climate change that is caused by human activity (Jager et al., 1996: 15 -20). The United Nations Framework Convention on Climate Change (UNFCCC) was signed at the Earth Summit in June 1992.Most State parties to the convention agreed to prevent destructive human interference with the system of the natural climate by reducing the emissions of carbon dioxide into the atmosphere (Read, 1994: 226 -227). Under the auspices of the UNFCCC, the Kyoto Protocol was ratified by most developed countries. The protocol committed developed countries to take action for reducing Greenhouse gas emissions. However, the protocol was not binding on the part of developing countries. The expected period for the reduction of emissions was estimated to start from the year 2008 to 2012 (Smith, 
2006: 82) but all in vain. The UNFCCC and Kyoto Protocol acknowledge the scientific consensus that climate change is caused by human activity by developed countries through industrialization. As a result, they both call for the reduction of Greenhouse gas emissions but silent about the harm that has been caused by industrialized countries on the African continent.

\section{Conclusion and Recommendations}

The Anthropogenic climate change is real and affecting the African economy. Industrialized countries are major contributors of the anthropogenic climate change through industrialization. Africa is not able to adapt to climate change due to poverty and the politicization of climate change. Consequently, these hamper smooth African economic growth and development. To accept that climate change is anthropogenic does not only imply the acceptance of Neo-colonization but also to hold industrialized countries morally responsible for anthropogenic climate change and its consequences. Therefore, it is recommended that climate science should be depoliticized. More importantly, Africa has a moral duty to strongly eradicate poverty through industrialization using renewable energy while industrialized countries have a moral duty to compensate Africa for the economic harm they have caused on Africa through industrialization. In this regard, their call for the reduction of Greenhouse gas emissions into the atmosphere is incomplete if they ignore the harm caused. In the same manner, the call to reduce Greenhouse gas emissions should also imply the call to restore the harm caused. The restoration of the harm caused should be done by way of compensating Africa since it is the most affected part of the world. The initiative will then boost the African economy and as a result, Africa will be able to adapt to climate change.

\section{References}

Armah, A.K., Wiafe, G., Kpelle, D.G. (2005). Sea-level rise and coastal biodiversity in West Africa: a case study from Ghana. The UK. Cambridge University Press, 204-217.

Balling, J. r. (2005). Interactions of Desertification and Climate change. The UK. Cambridge University Press.

Brunner, J., Justice, C. O., Putz F. E., Wilkie, D., (2005). Climate change in sub-Saharan Africa: assumptions, realities and future investments. UK. Cambridge University Press, 172-181.

Eze, E. C. (ed) (1998). African Philosophy: An Anthology. Massachusetts. Blackwell Publishers Ltd.

Hulme, M. (2009). Why We Disagree About Climate Change: Understanding Controversy, Inaction and Opportunity. New York. Cambridge University Press.

IPCC (2007). Climate Change 2007: Synthesis Report. Contribution of Working Groups I, II and III to Fourth Assessment Report of the Intergovernmental Panel on Climate Change [Core Writing Team, Pachauri, R.K and Reisinger, A. (eds)]. IPCC, Geneva, Switzerland, 104pp https:www.ipcc.ch/pdf/assessmentreport/ar4/syr/ar4syrfullreport.pdf (accessed on the $22^{\text {nd }}$ July 2015).

Jager, J. (1996). Politics of Climate Change: A European Perspective. London. Routledge.

Kyoto Protocol (2011). United Nations Framework Convention on Climate Change. http://unfccc.int/kyotoprotocol/items/2830phpaccessed on the $3^{\text {rd }}$ November 2011.

Moran, A. (2010). Climate Change: The Facts. Australia. Institute of Public Affairs.https://ipa.org.au/library/publication/1321487125_document_moran_clir (accessed on the $06^{\text {th }}$ January 2016).

Mwangi, O. G. (2010). Climate Change, hydro-politics and Security in Lesotho. South Africa. Institute of Security Studies.

Pojman, L. P. \& Pojman P. (2008). Environmental Ethics: Readings in theory and Application. Belmont. Thomson Wadsworth.

Ramose, M. B. (1999). African Philosophy Through Ubuntu. Harare. Mond Books Publishers.

Read, P. (1994). Responding to Global Warming. The Technology, Economics and Politics of Sustainable Energy: London: Zed Books LTD.

Smith, M. (2006). Just One Planet: Poverty, Justice and Climate Change. UK. Practical Action Publishing.

VaNDeVeer, D. \& Pierce, C. (2003). The Environmental Ethics and Policy Book. USA. Wadsworth.

Van Wyk, J. (2010). The African Union's Response to Climate Change and Climate Security. South Africa. Institute of Security Studies. 